\title{
Diabetes Mellitus and Site-specific Colorectal Cancer Risk in Korea: A Case-control Study
}

\author{
Hyeongtaek Woo' ${ }^{1}$ Jeeyoo Lee ${ }^{1,2}$, Jeonghee Lee ${ }^{3}$, Ji Won Park, ${ }^{4,5}$ Sungchan Park', Jeongseon Kim³, Jae Hwan Oh, \\ Aesun Shin ${ }^{1,3}$ \\ ${ }^{1}$ Department of Preventive Medicine, Seoul National University College of Medicine, Seoul; ${ }^{2}$ Department of Nutritional Science and Food Manage- \\ ment, Ewha Womans University, Seoul; ${ }^{3}$ Molecular Epidemiology Branch, Division of Cancer Epidemiology and Prevention, Research Institute, Na- \\ tional Cancer Center, Goyang; ${ }^{4}$ Center for Colorectal Cancer, Research Institute and Hospital, National Cancer Center, Goyang; ${ }^{5}$ Department of Sur- \\ gery, Seoul National University Hospital, Seoul, Korea
}

Objectives: Previous large-scale cohort studies conducted in Korea have found a positive association between diabetes mellitus (DM) and colorectal cancer (CRC) in men only, in contrast to studies of other populations that have found significant associations in both men and women.

Methods: A total of 1070 CRC cases and 2775 controls were recruited from the National Cancer Center, Korea between August 2010 and June 2013. Self-reported DM history and the duration of DM were compared between cases and controls. Odds ratios (ORs) and $95 \%$ confidence intervals (Cls) were calculated by binary and polytomous logistic regression models.

Results: DM was associated with an elevated risk of $\mathrm{CRC}$ in both men (OR, 1.47; $95 \% \mathrm{Cl}, 1.13$ to 1.90$)$ and women (OR, $1.92 ; 95 \% \mathrm{Cl}$, 1.24 to 2.98). This association remained when we controlled for age, body mass index, alcohol consumption, and physical activity level. In sub-site analyses, DM was associated with distal colon cancer risk in both men (multivariate $\mathrm{OR}, 2.04 ; 95 \% \mathrm{Cl}, 1.39$ to 3.00 ) and women (multivariate $\mathrm{ORs}, 1.99 ; 95 \% \mathrm{Cl}, 1.05$ to 3.79 ), while DM was only associated with rectal cancer risk in women (multivariate OR, 2.05; $95 \% \mathrm{Cl}, 1.10$ to 3.82). No significant association was found between DM and proximal colon cancer risk in either men (multivariate $\mathrm{OR}, 1.45 ; 95 \% \mathrm{Cl}, 0.88$ to 2.41 ) or women (multivariate $\mathrm{OR}, 1.79 ; 95 \% \mathrm{Cl}, 0.78$ to 4.08 ).

Conclusions: Overall, DM was associated with an increased risk of CRC in Koreans. However, potential over-estimation of the ORs should be considered due to potential biases from the case-control design.

Key words: Diabetes mellitus, Colorectal neoplasms, Colonic neoplasms

\section{INTRODUCTION}

Received: April 30, 2015 Accepted: December 22, 2015

Corresponding author: Aesun Shin, MD, PhD

103 Daehak-ro, Jongno-gu, Seoul 03080, Korea

Tel: +82-2-740-8331, Fax: +82- 2-747-4830

E-mail: shinaesun@snu.ac.kr

This is an Open Access article distributed under the terms of the Creative Commons Attribution Non-Commercial License (http://creativecommons.org/licenses/by$\mathrm{nc} / 3.0 /$ ) which permits unrestricted non-commercial use, distribution, and reproduction in any medium, provided the original work is properly cited.
According to the Korean Central Cancer Registry, colorectal cancer (CRC) is the third most common cancer in Korea, and the burden of CRC is rapidly increasing [1]. As the prevalence of diabetes mellitus (DM) in the Korean population has increased, it has become a major cause of morbidity and mortality in Korea [2]. It has been well established that diabetes is an independent risk factor for cardiovascular diseases in both men and women [3]. According to a recent meta-analysis, DM is also associated 
with a higher risk of gastric [4], lung [5], liver [6], pancreas [6], and breast cancer [7], but insufficient evidence exists regarding prostate cancer [8]. A history of DM has generally been associated with an elevated risk of colorectal cancer. A potential biological mechanism for increased CRC risk among individuals with DM is that hyperinsulinemia following insulin resistance affects colorectal epithelial cell proliferation, possibly having a tumorigenic effect [9]. Additionally, the overexpression of insulin receptors can affect colon tumorigenesis in DM patients [10]. Larsson et al. [11] found that diabetes was associated with an increased risk of CRC in both men and women in their metaanalysis. Two recent meta-analyses also reported a positive association between DM and CRC risk in both men and women $[12,13]$. In Korea, three reports have been published on the association between DM and colorectal polyps [14-16]. However, limited data are available regarding CRC in the Korean population. Two large-scale cohort studies have been conducted in Korea, and both studies showed a positive association between DM and CRC in men only $[17,18]$. Thus, additional epidemiologic studies are needed to assess the relationship between DM and CRC.

In order to clarify the effect of diabetes on CRC risk according to gender and cancer sub-site, we conducted a hospitalbased case-control study with 1070 colorectal cases and 2775 controls.

\section{METHODS}

\section{Study Participants}

We contacted newly diagnosed CRC patients when they were admitted to the Center for Colorectal Cancer, National Cancer Center, Korea between August 2010 and June 2013. We contacted 1259 of the 1427 eligible patients, and 1070 patients agreed to participate in the study and provided informed consent. We selected controls from subjects who visited the same hospital for a health screening program administered by the National Health Insurance Service, which provided insurance coverage to approximately $98 \%$ of the Korean population [19] during the period from March 2010 to November 2013. A total of 5936 participants completed a lifestyle questionnaire and a food frequency questionnaire. We excluded participants with inappropriate calorie intake ( $\leq 500 \mathrm{kcal} / \mathrm{d}$ or $\geq 4000 \mathrm{kcal} /$ $d, n=9)$ from the analysis. From the remaining 5927 participants, 2775 were age-matched (at five-year intervals) and gender-matched at a 1:3 ratio with 925 CRC patients who com- pleted a food frequency questionnaire. In addition, 145 CRC cases who did not a complete food frequency questionnaire were included in the current analysis. Therefore, a total of 3845 subjects (1070 cases and 2775 controls) were included in the analysis. In this study, we defined the proximal colon as including the cecum, ascending colon, hepatic flexure, transverse colon, and splenic flexure; the distal colon as including the descending colon, sigmoid-descending colon junction, and sigmoid colon; and the rectum as including the rectosigmoid colon and the rectum. All participants provided written informed consent to participate, and the study protocol was approved by the institutional review board (IRB) of the National Cancer Center (IRB no. NCCNCS-10-350).

\section{Data Collection}

The study participants answered questions about their age, marital status, education level, cigarette smoking and alcohol drinking habits, intake of charred meat, household income, regular exercise status, and family history of cancer, and the survey was administered by trained interviewers using a structured questionnaire. In cases, the patient's height and weight were measured before surgery, and in controls they were measured during a health examination. The body mass index (BMI) was calculated by dividing weight by height squared and categorized as underweight $\left(\mathrm{BMl}<18 \mathrm{~kg} / \mathrm{m}^{2}\right)$, normal (BMI 18 to $\left.24.9 \mathrm{~kg} / \mathrm{m}^{2}\right)$, and overweight $\left(\mathrm{BMI} \geq 25 \mathrm{~kg} / \mathrm{m}^{2}\right)$. Engaging in regular exercise was defined as a positive response to the question "Do you exercise regularly?" DM status was defined on the basis of a self-report. Participants were asked if a physician had ever told them that they had DM and what age they were diagnosed.

\section{Statistical Analysis}

Categorical data are presented as actual numbers and percentages. The $p$-values were calculated using the chi-square test and the Cochran-Mantel-Haenszel chi-square test with adjustments for age.

The association between DM and CRC was evaluated using binary logistic regression and polytomous logistic regression. The multivariate analysis included covariates that changed the odds ratio (OR) more than $10 \%$ compared to the corresponding reduced model.

In order to deal with missing data in covariates, we created a dummy variable for the missing category and included such dummy variables as covariates in the multivariate logistic re- 
gression.

All analyses were performed using SAS version 9.4 (SAS Institute, Inc., Cary, NC, USA).

\section{RESULTS}

Table 1 shows the general characteristics of study subjects according to gender. Among men, significant differences were found between cases and controls in age, marital status, education level, household income, BMI, alcohol consumption, regular exercise, family history of cancer, and family history of colorectal cancer. In women, significant differences were found between cases and controls in marital status, educational level, household income, BMI, smoking status, regular exercise, and family history of cancer.

In men, $15.7 \%$ of CRC cases (113/721) reported a history of diabetes, compared with $9.8 \%$ of controls (184/1878). In women, $11.5 \%$ of CRC cases (40/349) reported a history of diabetes, compared with $5.9 \%$ of controls (53/897).

The multivariate ORs for the association between DM and CRC were 1.50 (95\% confidence interval [CI], 1.15 to 1.97) and 1.97 ( $95 \% \mathrm{Cl}, 1.23$ to 3.17$)$ for men and women, respectively (Table 2).

We also conducted sub-site analyses. In men, a history of diabetes was associated with an increased risk of distal colon cancer (multivariate $\mathrm{OR}, 2.04 ; 95 \% \mathrm{Cl}, 1.39$ to 3.00 ) but was not associated with a risk of proximal colon cancer (multivariate $\mathrm{OR}, 1.45 ; 95 \% \mathrm{Cl}, 0.88$ to 2.41 ) or rectal cancer (multivariate OR, $1.23 ; 95 \% \mathrm{Cl}, 0.87$ to 1.76 ). In women, a history of diabetes was associated with an increased risk of distal colon cancer (multivariate $\mathrm{OR}, 1.99 ; 95 \% \mathrm{Cl}, 1.05$ to 3.79 ) and rectal cancer (multivariate $\mathrm{OR}, 2.05 ; 95 \% \mathrm{Cl}, 1.10$ to 3.82 ) but was not associated with a risk of proximal colon cancer (multivariate $\mathrm{OR}, 1.79$; $95 \% \mathrm{Cl}, 0.78$ to 4.08 ) (Table 2). In men, the adjusted OR for subjects with a duration of DM of 10 years or longer was similar to that of subjects who had a history of DM for less than 10 years. However, in women, subjects with a duration of DM of less than 10 years exhibited the highest adjusted OR (Table 3).

\section{DISCUSSION}

In this study, DM was significantly associated with an increased risk of CRC in both men and women, and this association remained present after adjusting for age, BMl, charred meat consumption, alcohol consumption, and physical activi- ty. Previous studies have also found an association between CRC risk and DM status. Larsson et al. [11] reported that DM was associated with CRC risk in both men and women in their meta-analysis. In more recent meta-analyses, this association remained unchanged $[12,13]$. In Korea, several studies have found a relationship between DM and colorectal polyps [1416]. However, to our knowledge, only two studies have investigated the association between DM and CRC risk in Korea. Jee et al. [17] conducted a prospective cohort study, finding that DM status was only associated with CRC risk in men. Another prospective cohort study conducted by Shin et al. [18] likewise found a significant association between CRC risk and a fasting glucose level of $126 \mathrm{mg} / \mathrm{dL}$ or more only in men. In order to explain the association between DM and CRC risk, a hypothesis involving hyperinsulinemia has been proposed [20]. According to this hypothesis, individuals with DM do not use insulin properly, which manifests as insulin resistance. This leads to a chronic hyperinsulinemic state and the elevation of insulin-like growth factor -1 levels, which then play a crucial role in the proliferation of cells and, finally, the occurrence of CRC $[19,20]$. In addition to the hyperinsulinemia hypothesis, elevated insulin receptor protein expression in colonic tumors has been proposed as a possible biological mechanism for colonic tumorigenesis because in vivo studies have shown that insulin receptors contribute to cell transformation [10].

Interestingly, DM was associated with overall CRC risk, but the association depended upon gender and the sub-site of the lesion. In our study, woman DM patients showed a stronger association than man DM patients with overall CRC risk. However, the $p$-value for the interaction did not indicate statistical significance. Recent meta-analyses have focused on gender-specific differences in diabetes and CRC risk. Wu et al. [21] found that men showed a stronger association between DM and colon cancer, while other studies have found a very similar association among men and women $[22,23]$. A hormonal difference between men and women has been suggested as an explanation of gender discrepancies, but no consistent effect of gender hormones on CRC incidence has been found. Gunter et al. [24] conducted a case-cohort study and found that endogenous estradiol was associated with an increased risk of colorectal cancer. Additionally, several in vitro studies have supported the mitogenic effect of estrogen on large intestine cells $[25,26]$. However, some studies have reported that estrogen may have a protective function against serious outcomes of hyperinsulinemia $[27,28]$. 
Table 1. General characteristics of study subjects

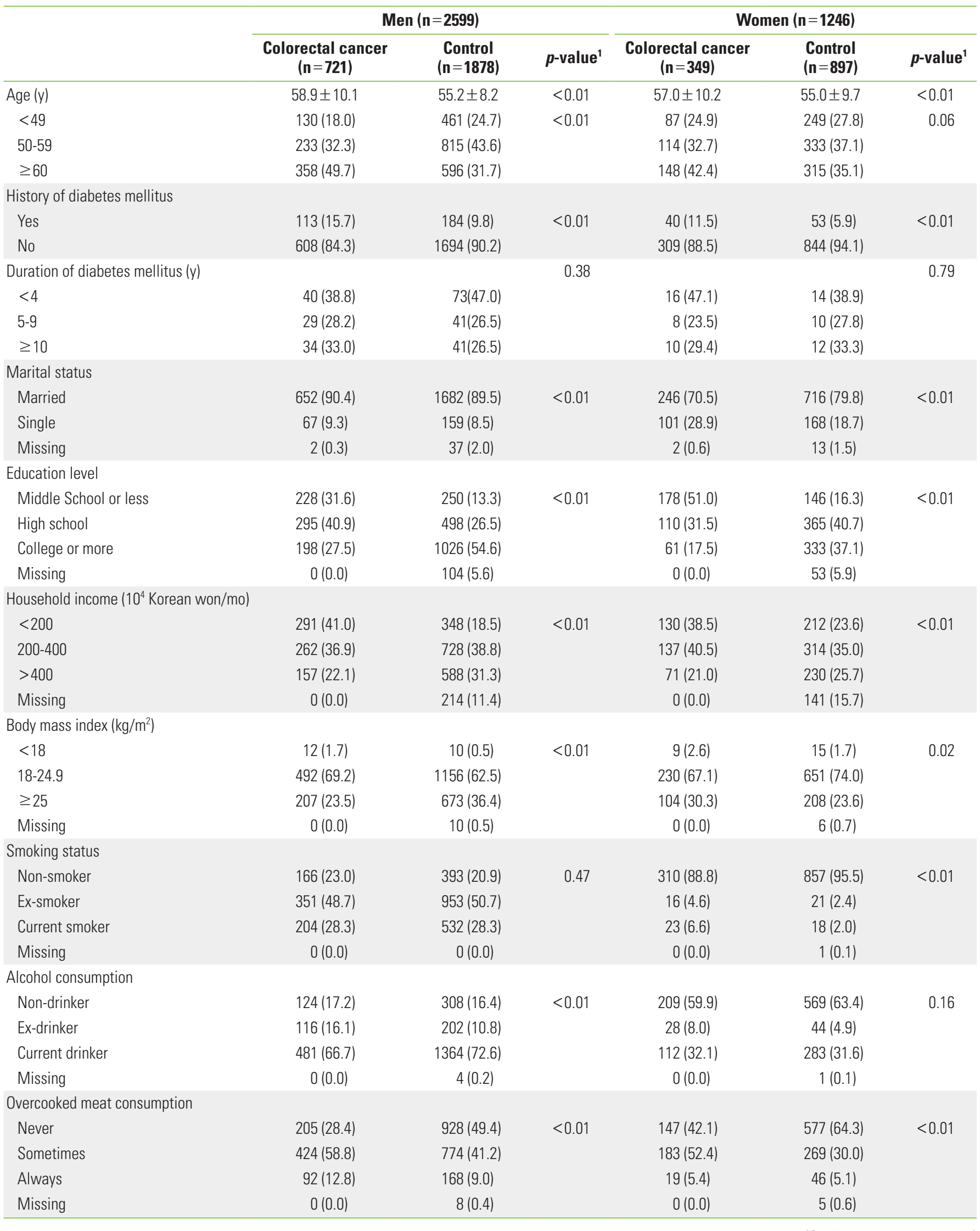


Table 1. Continued from the previous page

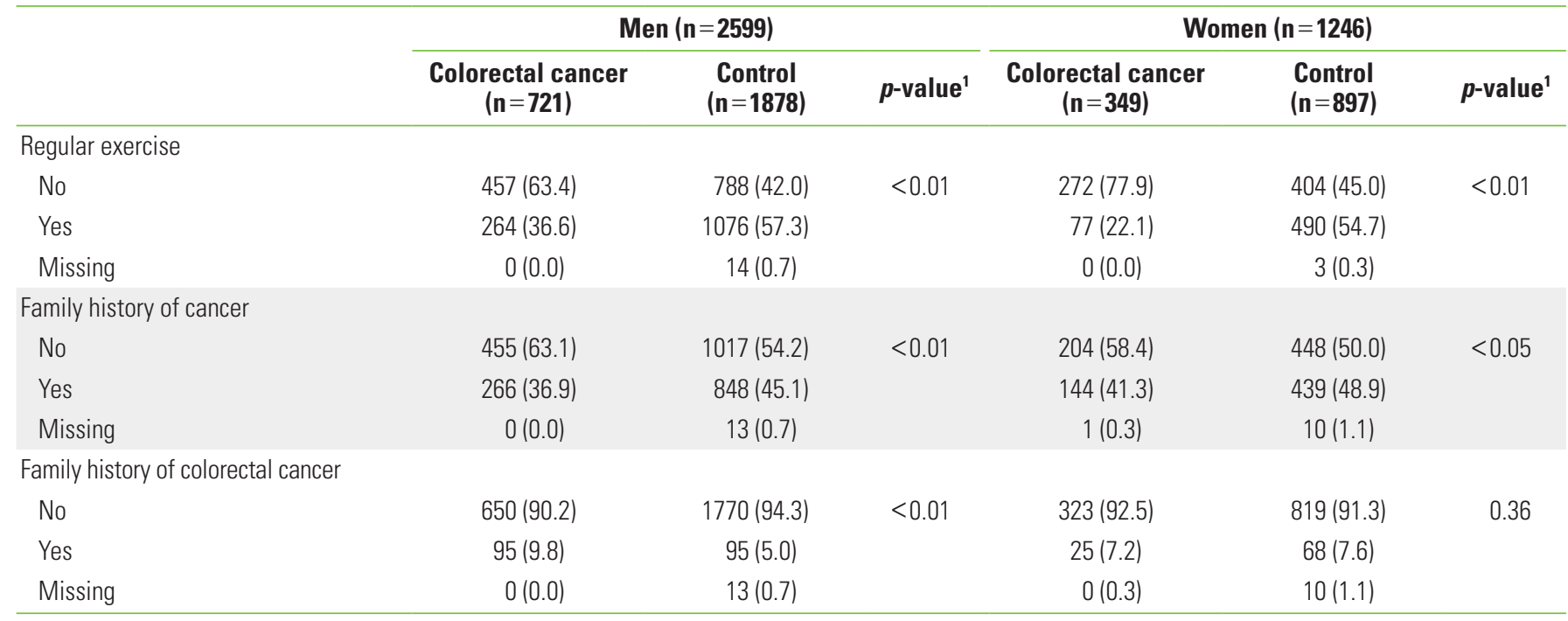

Values are presented as number (\%).

${ }^{1} t$-test for continuous variables and Pearson chi-square test for categorical variables.

Table 2. Odds ratios (ORs) and $95 \%$ confidence intervals (Cls) of overall and sub-sites of colorectal cancer risk in relation to history of diabetes mellitus (DM)

\begin{tabular}{|c|c|c|c|c|c|c|c|c|c|}
\hline & \multirow{2}{*}{$\begin{array}{c}\text { Site } \\
\text { (for cases) }\end{array}$} & \multicolumn{4}{|c|}{ Men $(n=2599)$} & \multicolumn{4}{|c|}{ Women $(n=1196)$} \\
\hline & & $\begin{array}{c}\text { No. of } \\
\text { participants }\end{array}$ & $\begin{array}{c}\text { No.of } \\
\text { DM (\%) }\end{array}$ & $\begin{array}{l}\text { Age-adjusted } \\
0 R^{2}(95 \% \mathrm{Cl})\end{array}$ & $\begin{array}{l}\text { Multivariate }^{1} \\
\text { OR }^{2} \text { (95\% CI) }\end{array}$ & $\begin{array}{c}\text { No. of } \\
\text { participants }\end{array}$ & $\begin{array}{c}\text { No. of } \\
\text { DM (\%) }\end{array}$ & $\begin{array}{c}\text { Age-adjusted } \\
\mathrm{OR}^{2}(95 \% \mathrm{CI})\end{array}$ & $\begin{array}{l}\text { Multivariate }^{1} \\
\text { OR }^{2}(95 \% \text { CI) }\end{array}$ \\
\hline Controls & & 1878 & $184(9.8)$ & 1.00 (reference) & 1.00 (reference) & 897 & $53(5.9)$ & 1.00 (reference) & 1.00 (reference) \\
\hline \multirow[t]{4}{*}{ Cases } & Overall & 721 & $113(15.7)$ & $1.47(1.13,1.90)$ & $1.53(1.16,2.01)$ & 349 & $40(11.5)$ & $1.92(1.24,2.98)$ & $1.95(1.20,3.17)$ \\
\hline & Proximal & 137 & $21(15.3)$ & $1.44(0.88,2.37)$ & $1.50(0.90,2.50)$ & 77 & $8(10.4)$ & $1.59(0.72,3.52)$ & $1.74(0.76,4.00)$ \\
\hline & Distal & 210 & $43(20.5)$ & $2.02(1.39,2.95)$ & $2.06(1.40,3.04)$ & 129 & $15(11.6)$ & $2.02(1.09,3.74)$ & $1.97(1.03,3.79)$ \\
\hline & Rectum & 374 & $49(13.1)$ & $1.19(0.84,1.68)$ & $1.25(0.87,1.79)$ & 143 & $17(11.9)$ & $2.04(1.13,3.67)$ & $2.02(1.07,3.82)$ \\
\hline
\end{tabular}

${ }^{1}$ Adjusted for age, body mass index, alcohol consumption, overcooked meat consumption and physical activity.

${ }^{2} \mathrm{OR}$ estimates for overall colorectal cancer by binary logistic regression and subsite specific colorectal cancer by polytomous logistic regression.

Table 3. Odds ratios (ORs) and 95\% confidence intervals (Cls) of overall colorectal cancer (CRC) risk in relation to duration of diabetes mellitus (DM)

\begin{tabular}{|c|c|c|c|c|c|c|}
\hline & \multicolumn{2}{|c|}{ No DM } & \multicolumn{2}{|c|}{$D M(<10 y)$} & \multicolumn{2}{|c|}{$\mathrm{DM}(\geq 10 \mathrm{y})$} \\
\hline & No. of CRC/Controls & $\begin{array}{l}\text { Multivariate }{ }^{1} \\
\text { OR }^{2}(95 \% \text { CI) }\end{array}$ & No. of CRC/Controls & $\begin{array}{l}\text { Multivariate }^{1} \\
\text { OR }^{2}(95 \% \text { CI })\end{array}$ & No. of CRC/Controls & $\begin{array}{c}\text { Multivariate }{ }^{1} \\
\text { OR }^{2}(95 \% \text { CI) }\end{array}$ \\
\hline Men & $608 / 1694$ & 1.00 (reference) & $69 / 114$ & $1.63(1.16,2.23)$ & $34 / 41$ & $1.64(0.98,2.73)$ \\
\hline Women & $309 / 844$ & 1.00 (reference) & $24 / 24$ & $2.31(1.21,4.39)$ & $10 / 12$ & $1.87(0.70,4.98)$ \\
\hline
\end{tabular}

${ }^{1}$ Adjusted for age, body mass index, alcohol consumption, overcooked meat consumption and physical activity.

${ }^{2}$ Binary logistic regression was used for analyses.

In the sub-site analyses, diabetes was associated with increased risk of distal colon cancer in men. In women, diabetes was associated with increased risk of distal colon cancer and rectal cancer. Although the point estimates of proximal colon cancer were similar to those of distal colon cancer, the results were not statistically significant in either men or women. Pre- vious studies have also found sub-site differences, although the findings have not been consistent. A large populationbased cohort study of postmenopausal women found a positive association between diabetes and proximal colon cancer risk, but not distal colon or rectal cancer risk [29]. Another large population-based retrospective cohort study found that 
diabetes was positively associated with proximal and distal colon cancer in men and with proximal and rectal cancer in women [30]. In addition to DM, some studies have found other risk factors that differentially affect CRC risk by sub-site [3133]. It has been suggested that a biological differences could be present among sub-sites. Some possible biological mechanisms may explain this relationship. First, embryological differences may affect the susceptibility of colorectal sub-sites to carcinogens; the area extending from the cecum to the proximal two thirds of the transverse colon originates from the midgut and the rest originates from the hindgut [34,35]. Second, differences in tumor methylation status, BRAF and KRAS mutation status, and DNA microsatellite instability may be associated with sub-site differences. Specifically, proximal tumors appear to be related to $\mathrm{CpG}$ island methylator phenotype (CIMP)-high and BRAF-mutated tumors, while distal tumors have been found to be mostly related to no-CIMP and microsatellite-stable tumors; additionally, tumors in the cecum appear to show a high frequency of KRAS mutations [36].

Our study has some limitations. First, because the control subjects were participants in a health screening program in Korea [37], the health-related behavior of the control subjects may have differed from that of the case subjects. Kim et al. [38] investigated the factors associated with participants attending a national cancer screening program in Korea and found that behavior, attitudes, and subject norms had important effects on participant intentions. Moreover, the DM status of the controls may have been underestimated. According to the 2012 annual report of the National Health Screening Program of Korea, the self-reported prevalence rates of DM among subjects between 40 and 60 years of age and more than 60 years of age were $7.04 \%$ and $13.11 \%$, respectively [39]. However, according to the fourth Korea National Health and Nutrition Examination Survey, the corresponding prevalence rates of DM were $9.85 \%$ and $17.21 \%$ in 2007 to 2009 , respectively [2]. Since the controls were recruited from participants in a health screening program, the association between DM and CRC risk may have been overestimated. Second, the control subjects were only tested with the fecal occult blood test, which is a screening test for CRC; thus, CRC cases could have been misclassified. However, this is a relatively unlikely possibility because CRC is a rare disease. In addition, controls with colon polyps may have been included in this study. However, since colorectal polyps have risk factors similar to those associated with colorectal cancer, this misclassification would have skewed the results toward the null. Third, when we analyzed CRC risk in relation to the duration of DM, women with a duration of DM of less than 10 years exhibited the highest adjusted OR. This may have been due to surveillance bias or screening bias; CRC patients might have sought medical service more recently, and therefore they might have been more likely to be diagnosed with DM. Finally, because we used self-reported DM history, memory bias or recall bias leading to the misclassification of DM status may have affected our results. However, a validation study of self-reported DM history conducted in Japan supported its reliability [40].

In summary, in this study, we observed that DM was associated with an increased risk of CRC in Koreans. Due to the casecontrol study design, which is vulnerable to selection bias in a control group that was recruited from healthy individuals who participated in a national health screening program, the association could have been overestimated.

\section{ACKNOWLEDGEMENTS}

This research was funded by the National Research Foundation of Korea (2010-0010276, 2013R1A1A2A10008260) and the National Cancer Center, Korea (0910220, 1210141).

\section{CONFLICT OF INTEREST}

The authors have no conflicts of interest associated with the material presented in this paper.

\section{ORCID}

Hyeongtaek Woo http://orcid.org/0000-0003-3020-7400

Jeeyoo Lee $h t t p: / / o r c i d . o r g / 0000-0002-1470-7504$

Ji Won Park https://orcid.org/0000-0003-0046-8175

Jeongseon Kim http://orcid.org/0000-0002-0889-2686

Jae Hwan Oh http://orcid.org/0000-0002-5883-5815

Aesun Shin http://orcid.org/0000-0002-6426-1969

\section{REFERENCES}

1. Korea Central Cancer Registry, National Cancer Center. Annual report of cancer statistics in Korea in 2012. Sejong: Ministry of Health and Welfare; 2014, p. 19 (Korean).

2. Kim DJ. The epidemiology of diabetes in Korea. Diabetes Metab J 2011;35(4):303-308.

3. Grundy SM, Benjamin IJ, Burke GL, Chait A, Eckel RH, Howard 
$\mathrm{BV}$, et al. Diabetes and cardiovascular disease: a statement for healthcare professionals from the American Heart Association. Circulation 1999;100(10):1134-1146.

4. Shimoyama S. Diabetes mellitus carries a risk of gastric cancer: a meta-analysis. World J Gastroenterol 2013;19(40):6902-6910.

5. Lee JY, Jeon I, Lee JM, Yoon JM, Park SM. Diabetes mellitus as an independent risk factor for lung cancer: a meta-analysis of observational studies. Eur J Cancer 2013;49(10):2411-2423.

6. Sasazuki S, Charvat H, Hara A, Wakai K, Nagata C, Nakamura K, et al. Diabetes mellitus and cancer risk: pooled analysis of eight cohort studies in Japan. Cancer Sci 2013;104(11):1499-1507.

7. Boyle P, Boniol M, Koechlin A, Robertson C, Valentini F, Coppens $\mathrm{K}$, et al. Diabetes and breast cancer risk: a meta-analysis. $\mathrm{Br} J$ Cancer 2012;107(9):1608-1617.

8. Hwang IC, Park SM, Shin D, Ahn HY, Rieken M, Shariat SF. Metformin association with lower prostate cancer recurrence in type 2 diabetes: a systematic review and meta-analysis. Asian Pac J Cancer Prev 2015;16(2):595-600.

9. Tran TT, Naigamwalla D, Oprescu Al, Lam L, McKeown-Eyssen $\mathrm{G}$, Bruce WR, et al. Hyperinsulinemia, but not other factors associated with insulin resistance, acutely enhances colorectal epithelial proliferation in vivo. Endocrinology 2006;147(4): 1830-1837.

10. Kiunga GA, Raju J, Sabljic N, Bajaj G, Good CK, Bird RP. Elevated insulin receptor protein expression in experimentally induced colonic tumors. Cancer Lett 2004;211(2):145-153.

11. Larsson SC, Orsini N, Wolk A. Diabetes mellitus and risk of colorectal cancer: a meta-analysis. J Natl Cancer Inst 2005;97(22): 1679-1687.

12. Guraya SY. Association of type 2 diabetes mellitus and the risk of colorectal cancer: a meta-analysis and systematic review. World J Gastroenterol 2015;21(19):6026-6031.

13. Luo S, Li JY, Zhao LN, Yu T, Zhong W, Xia ZS, et al. Diabetes mellitus increases the risk of colorectal neoplasia: an updated meta-analysis. Clin Res Hepatol Gastroenterol 2015. doi: http:// doi.org/10.1016/j.clinre.2015.05.021.

14. Cha JM, Lee Jl, Joo KR, Shin HP, Jeun JW, Lim JU. Prediabetes is associated with a high-risk colorectal adenoma. Dig Dis Sci 2013;58(7):2061-2067.

15. Rampal S, Yang MH, Sung J, Son HJ, Choi YH, Lee JH, et al. Association between markers of glucose metabolism and risk of colorectal adenoma. Gastroenterology 2014;147(1):78-87.

16. Suh S, Kang M, Kim MY, Chung HS, Kim SK, Hur KY, et al. Korean type 2 diabetes patients have multiple adenomatous polyps compared to non-diabetic controls. J Korean Med Sci 2011;
26(9):1196-1200.

17. Jee SH, Ohrr H, Sull JW, Yun JE, Ji M, Samet JM. Fasting serum glucose level and cancer risk in Korean men and women. JAMA 2005;293(2):194-202.

18. Shin HY, Jung KJ, Linton JA, Jee SH. Association between fasting serum glucose levels and incidence of colorectal cancer in Korean men: the Korean Cancer Prevention Study-II. Metabolism 2014;63(10):1250-1256.

19. Kim L, Kim JA, Kim S. A guide for the utilization of Health Insurance Review and Assessment Service national patient samples. Epidemiol Health 2014;36:e2014008.

20. Giovannucci E. Insulin and colon cancer. Cancer Causes Control 1995;6(2):164-179.

21. Wu L, Yu C, Jiang H, Tang J, Huang HL, Gao J, et al. Diabetes mellitus and the occurrence of colorectal cancer: an updated meta-analysis of cohort studies. Diabetes Technol Ther 2013; 15(5):419-427.

22. Sun $L$, Yu S. Diabetes mellitus is an independent risk factor for colorectal cancer. Dig Dis Sci 2012;57(6):1586-1597.

23. Krämer HU, Schöttker B, Raum E, Brenner H. Type 2 diabetes mellitus and colorectal cancer: meta-analysis on sex-specific differences. Eur J Cancer 2012;48(9):1269-1282.

24. Gunter MJ, Hoover DR, Yu H, Wassertheil-Smoller S, Rohan TE, Manson JE, et al. Insulin, insulin-like growth factor-l, endogenous estradiol, and risk of colorectal cancer in postmenopausal women. Cancer Res 2008;68(1):329-337.

25. English MA, Kane KF, Cruickshank N, Langman MJ, Stewart $\mathrm{PM}$, Hewison M. Loss of estrogen inactivation in colonic cancer. J Clin Endocrinol Metab 1999;84(6):2080-2085.

26. Arai N, Ström A, Rafter JJ, Gustafsson JA. Estrogen receptor beta mRNA in colon cancer cells: growth effects of estrogen and genistein. Biochem Biophys Res Commun 2000;270(2): 425-431.

27. Newcomb PA, Storer BE. Postmenopausal hormone use and risk of large-bowel cancer. J Natl Cancer Inst 1995;87(14):10671071

28. Calle EE, Miracle-McMahill HL, Thun MJ, Heath CW Jr. Estrogen replacement therapy and risk of fatal colon cancer in a prospective cohort of postmenopausal women. J Natl Cancer Inst 1995; 87(7):517-523.

29. Limburg PJ, Anderson KE, Johnson TW, Jacobs DR Jr, Lazovich $D$, Hong $C P$, et al. Diabetes mellitus and subsite-specific colorectal cancer risks in the lowa Women's Health Study. Cancer Epidemiol Biomarkers Prev 2005;14(1):133-137.

30. Sikdar KC, Walsh SJ, Roche M, Jiang Y, Syrowatka A, Collins KD. 
Diabetes and sex-specific colorectal cancer risks in Newfoundland and Labrador: a population-based retrospective cohort study. Can J Public Health 2013;104(2):e101-e107.

31. Shin A, Joo J, Bak J, Yang HR, Kim J, Park S, et al. Site-specific risk factors for colorectal cancer in a Korean population. PLoS One 2011;6(8):e23196.

32. Mahipal A, Anderson KE, Limburg PJ, Folsom AR. Nonsteroidal anti-inflammatory drugs and subsite-specific colorectal cancer incidence in the Lowa Women's Health Study. Cancer Epidemiol Biomarkers Prev 2006;15(10):1785-1790.

33. Hjartåker A, Aagnes B, Robsahm TE, Langseth H, Bray F, Larsen IK. Subsite-specific dietary risk factors for colorectal cancer: a review of cohort studies. J Oncol 2013;2013:703854.

34. Gervaz P, Bucher P, Morel P. Two colons-two cancers: paradigm shift and clinical implications. J Surg Oncol 2004;88(4):261-266.

35. Bufill JA. Colorectal cancer: evidence for distinct genetic categories based on proximal or distal tumor location. Ann Intern Med 1990;113(10):779-788.
36. Yamauchi M, Morikawa T, Kuchiba A, Imamura Y, Qian ZR, Nishihara R, et al. Assessment of colorectal cancer molecular features along bowel subsites challenges the conception of distinct dichotomy of proximal versus distal colorectum. Gut 2012;61(6):847-854.

37. Lee WC, Lee SY. National health screening program of Korea. J Korean Med Assoc 2010;53(5):363-370 (Korean).

38. Kim RB, Park KS, Hong DY, Lee CH, Kim JR. Factors associated with cancer screening intention in eligible persons for national cancer screening program. J Prev Med Public Health 2010; 43(1):62-72 (Korean).

39. Ministry of Health and Welfare. National health screening statistical yearbook 2012. Seoul: National Health Insurance Service; 2013, p. 133 (Korean).

40. Goto A, Morita A, Goto M, Sasaki S, Miyachi M, Aiba N, et al. Validity of diabetes self-reports in the Saku diabetes study. J Epidemiol 2013;23(4):295-300. 